\title{
Immunohistochemical evaluation of osteopontin expression in triple-negative breast cancer
}

\author{
Magdalena Niedolistek ${ }^{1}$, Marta M. Fudalej ${ }^{1}$, Aleksandra Sobiborowicz ${ }^{1}$, Anna Liszcz ${ }^{1}$, \\ Michał P. Budzik² ${ }^{2}$ Maciej Sobieraj ${ }^{1}$, Janusz Patera ${ }^{3}$, Aleksandra Czerw ${ }^{4}$, Urszula Religioni ${ }^{5}$, \\ Maria Sobol ${ }^{6}$, Andrzej Deptała², Anna M. Badowska-Kozakiewicz²
}

\begin{abstract}
'Students' Scientific Organization of Cancer Cell Biology, Department of Cancer Prevention, Medical University of Warsaw, Warsaw, Poland

2Department of Cancer Prevention, Medical University of Warsaw, Warsaw, Poland ${ }^{3}$ Department of Pathomorphology, Military Institute of Health Services, Warsaw, Poland ${ }^{4}$ Department of Health Economics and Medical Law, Medical University of Warsaw, Warsaw, Poland

${ }^{5}$ Collegium of Business Administration, Warsaw School of Economics, Warsaw, Poland ${ }^{6}$ Department of Biophysics and Human Physiology, Medical University of Warsaw, Poland
\end{abstract}

Submitted: 17 June 2019

Accepted: 27 November 2019

Arch Med Sci

DOI: https://doi.org/10.5114/aoms.2020.93695

Copyright (c) 2020 Termedia \& Banach

\section{Abstract}

Introduction: Triple-negative breast cancer (TNBC) is associated with lack of expression of estrogen and progesterone receptors and HER2 and is the subgroup of breast cancers with the worst prognosis. Osteopontin is a phosphorylated glycoprotein whose overexpression may occur in pathological states such as cancers. The main purpose of our study was to evaluate the immunohistochemical expression of osteopontin in connection with the analysis of recognized clinical and pathological prognostic factors in primary sites of TNBC with and without lymph node metastases.

Material and methods: The immunohistochemical evaluation of osteopontin expression in 35 women with TNBC, chosen from a group of 726 patients, was performed. The material came from the excisional biopsies of primary breast cancers and total mastectomies.

Results: All patients showed expression of osteopontin, in most cases the expression of osteopontin rated at [+] (57.1\%) and [++] (42.9\%). Our study analyzed the relationship between the expression of osteopontin and traditional prognostic markers, such as the tumor grade, size, and lymph node involvement. We found a strong relationship only between the expression of osteopontin and the presence of lymph node metastases $(p \leq 0.0001)$. $93 \%$ of patients for whom the expression of osteopontin was determined at [++] had metastasis to lymph nodes and, for comparison, only $15 \%$ of women for whom the expression of osteopontin was rated at [+] showed the presence of metastases in the lymphatic nodes.

Conclusions: There is a correlation between osteopontin expression and the presence of lymph node metastases in TNBC, suggesting that osteopontin plays an important role in the invasiveness of TNBC.

Key words: immunohistochemistry, osteopontin, triple-negative breast cancer.

\section{Introduction}

Breast cancer is the second most common malignancy worldwide, comprising $12 \%$ of all invasive cancers. It is the most common female
Corresponding author: Marta M. Fudalej

Students' Scientific

Organization of Cancer Cell

Biology

Department of Cancer

Prevention

Medical University of Warsaw

81 Żwirki i Wigury Str.

02-091 Warsaw, Poland

E-mail:

marcioszka.m@gmail.com 
malignancy, especially in well-developed countries. Breast cancer biology consists of an immense network of dependencies between various proteins. One of the widely discussed signaling proteins playing key roles in cancer development is osteopontin (OPN). It was described for the first time by Senger et al. (1979), who indicated its role as a potential marker of epithelial cell transformation [1]. The name of osteopontin is associated with its function in the bone tissue. Osteopontin binds to the cellular surface, enhancing cell migration and adhesion. Moreover, it plays a role in several physiological and pathological processes such as maintenance and remodeling of bone integrity in response to tension or pressure, early cell immune reactions, dystrophic calcification, recurrent coronary artery stenosis, regulation of growth and differentiation of cancer cells, and development of metastases. It has also been shown that osteopontin takes part in the process of new blood vessel formation. Furthermore, osteopontin is necessary in cell adhesion, apoptosis, inflammatory processes, and wound healing [2].

Current studies concentrate on establishing the role of osteopontin in carcinogenesis. It is suspected to influence the development of distant metastases in malignancies of the tongue, esophagus, stomach, colon, pancreas, kidneys, endometrium and breast; however, the mechanism remains unclear. Moreover, high OPN concentration in breast cancer cells has been shown to be correlated with sooner local relapse and shorter overall survival (OS) [4].

The molecular subtype of breast cancer that tends to metastasize more commonly than others is called triple-negative breast cancer (TNBC). It is defined by lack of expression of estrogen receptor $(E R)$, progesterone receptor (PR) and human epidermal growth factor receptor 2 (HER2). Triple-negative breast cancer is diagnosed in $12-17 \%$ of all breast cancer cases. As the TNBC cells are frequently relatively heterogeneous and poorly differentiated, this cancer type is thought to run an aggressive course with rapid recurrences [3] and common development of distant metastases [5].

Compared to other subtypes of invasive breast cancer, TNBC is characterized by higher clinical stages on diagnosis, larger size (pT1-pT4) and lower histological grade (G1-G3) [6]. Triple-negative breast cancer tends to be more aggressive, with rapid growth of the tumor, to metastasize both to regional lymph nodes and distant organs and to present a much shorter time to relapse after treatment (on average 1-3 years). Metastases of TNBC are localized more often in the brain and lungs, while localizing in the bones less commonly than other types of breast cancer $[7,8]$. On the other hand, TNBC tend to have higher probability of a complete pathological response to neoadjuvant chemotherapy [9].

Due to more frequent occurrence of lymph node metastases in the case of TNBC and the same relationship between the presence of metastases and OPN expression, we decided to analyze the coexistence of loss of expression of breast cancer receptors (ER, PR, HER2) and expression of osteopontin.

The purpose of this study was to evaluate immunohistochemical expression of osteopontin in connection with the analysis of recognized clinical and pathological prognostic factors in primary sites of triple-negative breast cancer with and without lymph node metastases.

\section{Material and methods}

Material consisted of primary tumors of female breasts (726 patients) obtained from the excisional biopsies and total mastectomies. A total of 35 patients with triple-negative breast cancer confirmed by assessment of lack of the ER, PR and HER2 expression were selected for further testing. Tumor samples were fixed in $8 \%$ buffered formalin phosphate. After 24-hour fixation, material was dehydrated using alcohol in gradually increasing concentrations $(50,60,50,60,70,80,90,96 \%)$ of absolute alcohol and xylene and embedded in paraffin. Paraffin blocks were cut into serial sections $4 \mu \mathrm{m}$ in thickness. They were then stained using standard methods. In preparations stained with $\mathrm{H} \& \mathrm{E}$ the following determinations were carried out:

- type of neoplasm (WHO classification),

- tumor grade (G1-G3) including tubule formation, and intensity of division as well as the degree of neoplastic cell differentiation,

- mitotic index as the mean number of mitotic figures in neoplastic cells counted in 10 fields of vision at 400x magnification (surface area: $0.17 \mathrm{~mm}^{2}$ ).

Paraffin sections on slides covered with $2 \%$ saline solution (Sigma) in acetone and dried for 24 hours at $42^{\circ} \mathrm{C}$ were used for immunohistochemical examination. Before the staining procedure, the material underwent a routine deparaffinization process in gradually decreasing concentrations of alcohol. For immunohistochemical examination we used monoclonal antibodies in proper concentrations in 1\% BSA (Merck, Darmstadt, Germany). The following antibodies were used:

- Monoclonal Mouse Anti-Human Estrogen Receptor alpha, 1 : 50 dilution, clone: 1D5, code: IR654 (DAKO, Santa Clara, United States),

- Monoclonal Mouse Anti-Human Progesterone Receptor, 1 : 400 dilution, clone: PR636, code: IR068 (DAKO, Santa Clara, United States),

- Polyclonal Rabbit Anti-Human HER2 Protein using HercepTest, code: K5204 (DAKO, Santa Clara, United States), 
- Mouse monoclonal OPN antibody (AKm2A1), sc-21742 (Santa Cruz Biotechnology, Dallas, Texas, United States).

Sections were subsequently dewaxed in $x y-$ lene, gradually decreasing concentrations of alcohol and distilled water. The next step involved revealing the epitope by heating the slides in a buffer (derived from mixing $75 \mu$ of blocking buffer with $5 \mathrm{ml}$ PBS) for 1 hour. Afterwards, preparations were incubated with 50-100 $\mathrm{\mu l}$ (depending on the sample size) of anti-osteopontin antibody 1 : 50 solution for $30 \mathrm{~min}$. After incubation, preparations were rinsed three times in PBS for 5 minutes. The next step was incubation for 30 minutes with biotinylated secondary antibody (derived from mixing $75 \mu$ of blocking buffer with $5 \mathrm{ml}$ of PBS and $25 \mu$ lof biotinylated secondary antibody). After incubation, preparations were once again rinsed three times in PBS for 5 minutes. Next, preparations were incubated for 30 min with an $A B$ enzyme reagent that was previously prepared by combining avidin with biotinylated peroxidase in an equal ratio and diluted in PBS $(50 \mu \mathrm{l}$ of avidin, $50 \mu \mathrm{l}$ of biotinylated peroxidase and $2.5 \mathrm{ml}$ of PBS). After incubation, preparations were rinsed three times in PBS for 5 minutes. The next step was incubation in a peroxidase substrate (consisting of $2.5 \mathrm{ml}$ of distilled water, 5 drops of buffer, 1 drop of diaminobenzidine solution (DAB) and 1 drop of peroxidase) for about 5 minutes. The color of the preparations was controlled, then they were rinsed in tap water, stained for 5 minutes with Ehrlich's hematoxylin, differentiated in 1\% acidic alcohol and again rinsed in tap water. The preparations were then dehydrated in a series of alcohols with increasing concentrations and xylene and mounted in a DPX mountant (Merck, Darmstadt, Germany).

To interpret the results of immunohistochemical (IHC) staining computer image analysis and the program Lucia v. 4.21 were used. Stained nuclei, cytoplasm and cellular membrane of cancer cells were counted among 1000 cancer cells. OPN staining results were scored according to the percentage of positive cells as follows:

- [-] below $10 \%$ positive cells,

- [+] $10 \%$ positive cells,

- $[++]$ between $10 \%$ to $30 \%$ positive cells,

- $[+++]$ more than $30 \%$ positive cells.

The results were presented in the form of arithmetic means $(x \pm S D)$. The results were developed using the SPSS v. 12.0 PL Windows program. Pearson's quadrate test was used to verify the hypothesis of the independence of two features. Spearman's correlation coefficient values were calculated, and their significance was evaluated using Student's t-test. Differences were considered statistically significant at $p \leq 0.05$.

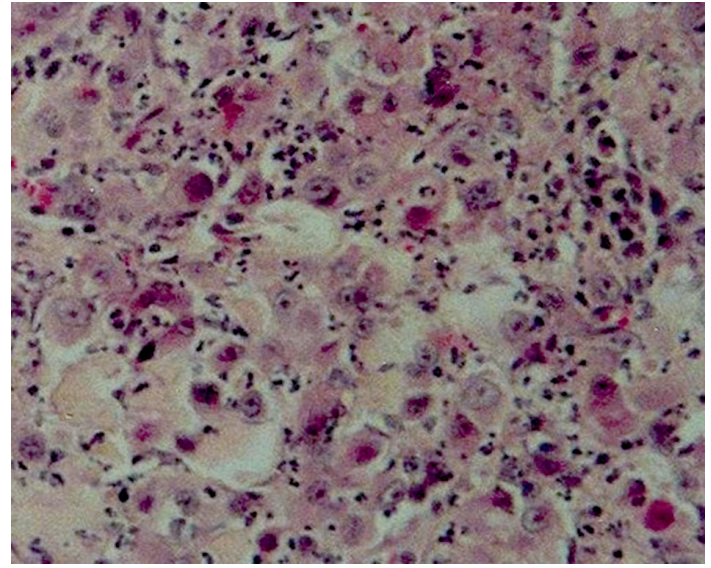

Figure 1. Histopathological image of triple-negative breast cancer (grade $3, \mathrm{H} \& \mathrm{E}$, original magnification, 200x)

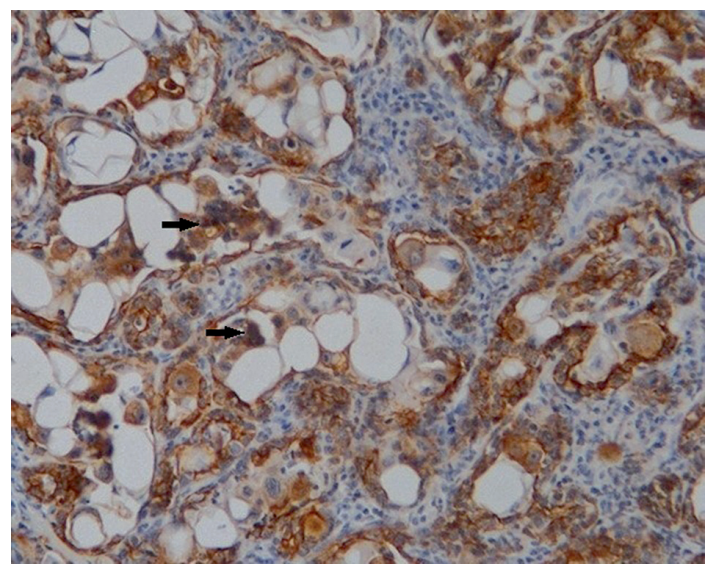

Figure 2. Immunohistochemical analysis of osteopontin expression in triple-negative breast cancer (positive staining images for OPN; original magnification, 400x)

\section{Results}

In our study patients with TNBC represented $4.8 \%$ of cases. Mean age of studied women was 57.1 years. Histological examination revealed the following percentages of TNBC tumors types: $89 \%$ - invasive ductal carcinomas (IDC) and 11\% - metaplastic carcinomas.

In the TNBC group, tumors evaluated as G2 (51\%) and G3 (42.9\%) were the most numerous. As far as tumor size is concerned, the most numerous group was represented by pT2 $(2-5 \mathrm{~cm})$ (57.1\% of cases), whereas $26 \%$ of tumors were below $2 \mathrm{~cm}$ in diameter, so they were evaluated as pT1. Remaining patients were diagnosed with tumors exceeding $5 \mathrm{~cm}$, and additionally 2 malignancies (6\%) infiltrated the chest (pT4). Lymph node involvement was detected in 17 cases (49\%) of TNBC (pN1 43\%; pN2 3\%; pN3 3\%). The correlation between nodal status (pN0-pN3), histological grade (G1-G3) and tumor size (pT1-pT4) is presented in Table I. 
In our study G1 tumors did not present lymph node involvement and their measurement was below $5 \mathrm{~cm}$. A statistically significant relationship was demonstrated between lymph node involvement and tumor size ( $p$ value $\leq 0.05$ ).

Age of examined patients with TNBC was within the range of 30 to 81 . Although the correlation between patient age and histological type of neoplasm was studied and no statistically significant relationships were found, IDC was most frequently examined in patients in the age range of 45 to 65 . In our study a statistically significant correlation was demonstrated between histological grade (G1-G3) and tumor size (pT1-pT4) $(p \leq 0.044)$, as well as between lymph node involvement (pNO-pN3) and tumor size of TNBC malignancies $(p \leq 0.049)$.

Moreover, in our analysis we assessed the relationship between patients' age and histological grade (G1-G3) and noted that young women were diagnosed with $\mathrm{G} 1$ breast cancer more frequently.

Analysis of the structure of increasing histological grading matched with patient age revealed that $66.7 \%$ of women at the age between 60 and
75 were diagnosed with G2 tumors, whereas patients over 75 years of age were diagnosed most frequently with G3 tumors - also $66.7 \%$ of cases. Interestingly, none of the patients over 60 years was diagnosed with the lowest grading, G1. To conclude, there is an evident increase of histological grading with patient age.

Through the use of immunohistochemical techniques, expression of osteopontin was detected in 35 cases of TNBC. OPN staining results were scored according to the percentage of positive cytoplasm staining based on the scale presented in Table II. In the studied group of 35 patients with TNBC all of them revealed OPN expression, mostly scored as [+] (57.1\%) and [++] (42.9\%). In the studied materials expression scored as [+++] was not detected.

In our study we assessed the correlation between expression of osteopontin and recognized clinical and pathological prognostic factors used in breast cancer diagnostics such as histological grade (G1-G3), tumor size (pT1-pT4), lymph node involvement (pNO-pN3) and expression of steroid receptors (ER, PR) and HER2. Among studied

Table I. Relationship between presence of nodal metastases (pN0-pN3), histological grade (G1-G3) and tumor size (pT1-pT4) in triple-negative breast cancer

\begin{tabular}{|c|c|c|c|c|c|c|c|c|c|}
\hline \multirow[t]{2}{*}{ Parameter } & \multicolumn{9}{|c|}{ Lymph nodes status } \\
\hline & pNO & $\%$ & pN1 & $\%$ & $\mathrm{pN} 2$ & $\%$ & pN3 & $\%$ & $P$-value \\
\hline \multicolumn{10}{|c|}{ Histological grade (G1-G3) } \\
\hline G1 & 2 & 11 & 0 & - & 0 & - & 0 & - & \multirow{3}{*}{0.055} \\
\hline $\mathrm{G} 2$ & 8 & 44 & 8 & 53 & 1 & 100 & 1 & 100 & \\
\hline G3 & 8 & 44 & 7 & 47 & 0 & - & 0 & - & \\
\hline \multicolumn{10}{|c|}{ Tumor size (pT1-pT4) } \\
\hline pT1 & 5 & 28 & 4 & 27 & 0 & - & 0 & - & \multirow{4}{*}{0.049} \\
\hline pT2 & 9 & 50 & 11 & 73 & 0 & - & 0 & - & \\
\hline pT3 & 2 & 11 & 0 & - & 1 & 100 & 1 & 100 & \\
\hline pT4 & 2 & 11 & 0 & - & 0 & - & 0 & - & \\
\hline
\end{tabular}

Table II. Scale of assessment of immunohistochemical staining for osteopontin in patients with triple-negative breast cancer

\begin{tabular}{|lcccc|}
\hline $\begin{array}{l}\text { Percent of stained } \\
\text { cancer cells }- \\
\text { positive cytoplasmatic } \\
\text { reaction }\end{array}$ & $\begin{array}{c}\text { Degree } \\
\text { of cytoplasmatic } \\
\text { staining in cancer } \\
\text { cells }\end{array}$ & $\begin{array}{c}\text { Assessment of OPN } \\
\text { cytoplasmatic } \\
\text { expression } \\
\text { in cancer cells }\end{array}$ & $\begin{array}{c}\text { Number of TNBC } \\
\text { with positive } \\
\text { cytoplasmatic } \\
\text { reaction }\end{array}$ & $\begin{array}{c}\text { Percent of TNBC } \\
\text { with positive } \\
\text { cytoplasmatic } \\
\text { reaction }\end{array}$ \\
\hline $10 \%$ & - & None & 0 & 0 \\
\hline$>10-30 \%$ & + & Weak & 20 & 57.1 \\
\hline$>30 \%$ & ++ & Intermediate & 0 & 42.9 \\
\hline OPN-OSteopontin, $T N B C-$ triple-negative breast cancer. & & Strong & 0 \\
\hline
\end{tabular}


Table III. Relationship between osteopontin expression and histological grade (G1-G3), tumor size (pT1-pT4), presence of nodal metastases (pNO-pN3)

\begin{tabular}{|c|c|c|c|c|c|}
\hline \multirow[t]{2}{*}{ Parameter } & \multicolumn{5}{|c|}{ Osteopontin expression } \\
\hline & - & + & ++ & +++ & $P$-value \\
\hline \multicolumn{6}{|c|}{ Histological grade (G) } \\
\hline G1 & 0 & $1(5 \%)$ & $1(7 \%)$ & 0 & \multirow{3}{*}{0.946} \\
\hline G2 & 0 & $10(50 \%)$ & 8 (53\%) & 0 & \\
\hline G3 & 0 & $9(45 \%)$ & $6(40 \%)$ & 0 & \\
\hline \multicolumn{6}{|l|}{ Tumor size (pT) } \\
\hline pT1 & 0 & $5(25 \%)$ & $4(27 \%)$ & 0 & \multirow{4}{*}{0.652} \\
\hline pT2 & 0 & $11(55 \%)$ & $9(60 \%)$ & 0 & \\
\hline pT3 & 0 & $2(10 \%)$ & $2(13 \%)$ & 0 & \\
\hline pT4 & 0 & $2(10 \%)$ & 0 & 0 & \\
\hline \multicolumn{6}{|c|}{ Nodal status (pN) } \\
\hline pNO & 0 & 17 (85\%) & $1(7 \%)$ & 0 & \multirow{2}{*}{$<0.001$} \\
\hline pN1-pN3 & 0 & $3(15 \%)$ & 14 (93\%) & 0 & \\
\hline
\end{tabular}

Table IV. Correlation between osteopontin expression and histological grade (G1-G3), tumor size (pT1-pT4), presence of nodal metastases (pNO-pN3) in patients with triple-negative breast cancer

\begin{tabular}{|lcccccccc|}
\hline & $\begin{array}{c}\text { Histological grade } \\
(\mathrm{G} 1-\mathrm{G} 3)\end{array}$ & \multicolumn{2}{c}{$\begin{array}{c}\text { Tumor size } \\
\text { (pT1-pT4) }\end{array}$} & \multicolumn{2}{c|}{$\begin{array}{c}\text { Nodal status } \\
\text { (pN0-pN3) }\end{array}$} & \multicolumn{2}{c|}{$\begin{array}{c}\text { Patient age } \\
\text { [years] }\end{array}$} \\
\cline { 2 - 9 } & $r$ & $P$-value & $r$ & $P$-value & $r$ & $P$-value & $r$ & $P$-value \\
\hline $\begin{array}{l}\text { Osteopontin } \\
\text { expression }\end{array}$ & -0.055 & 0.754 & -0.074 & 0.674 & 0.776 & $<0.001$ & -0.208 & 0.236 \\
\hline
\end{tabular}

factors we highlighted the correlation between lymph node involvement and osteopontin expression ( $p \leq 0.001$ ) (Table III). Nodal metastases were detected in $93 \%$ of patients with OPN expression scored as [++] (> 10-30\% positive cells), whereas only $15 \%$ of patients with OPN expression scored as [+] (10\% positive cells) revealed lymph node metastases (Table III). Given grading, tumor size and patient age, no statistically significant relation between them and osteopontin expression in sites of TNBC was detected (Table III and IV).

\section{Discussion}

Breast cancer is the second most common malignancy worldwide, right after lung cancer. Among women it is the most commonly diagnosed malignant tumor, causing $13 \%$ of deaths. Triple-negative breast cancer represents the least numerous group of breast cancers among women (12-20\%). Due to the rarity of TNBC, our study sample was not very extensive, including only 35 cases, demanding cautious interpretation of the results, which is a common problem in papers concerning infrequent malignancies. As this type of breast cancer is characterized by the worst prognosis, it seems crucial to find new markers connected with well-established prognostic factors such as: expression of estrogen, progesterone and HER2 receptors, histological grading, tumor size and nodal status $[7,10]$. These findings may influence selection of effective therapy for TNBC in the future.

For the time being researchers are looking for new prognostic and predictive markers for TNBC, and osteopontin might fulfill this role. It has been widely studied not only regarding breast cancer, but also non-small-cell lung carcinoma (NSCLC), gastric cancer, liver cancer, head and neck cancers and prostate cancer.

In our study mean age of studied patients was 57 and similar results were obtained by WangBrown et al. (2015) (mean age 58), whereas slightly different results were achieved by other researchers, e.g. Bhoo-Pathy et al. (2015) and Dent et al. (2007) (mean age 53) and also Nabi et al. (2016) (mean age 47) [11-13].

Given the tumor size, the largest group of triple-negative breast cancer encompassed tumor assessed as pT2 (57.1\%), whereas $26 \%$ of tumors 
were below $2 \mathrm{~cm}$. Remaining patients were diagnosed with tumors exceeding $5 \mathrm{~cm}$, while $2 \mathrm{ma}$ lignancies (6\%) infiltrated the chest (pT4). Dent et al. (2007) and Badowska-Kozakiewicz et al. (2018) obtained similar results - they confirmed in their study that pT2 cancers (accordingly: $55.6 \%$ and $62.1 \%$ ) comprised the largest group of triple-negative neoplasms, and also Fan et al. (2015) reported that among studied TNBC patients, 50\% were diagnosed with pT2 tumors [13-15].

In our study lymph nodes metastases were detected in $49 \%$ of patients with TNBC $(43 \%-p N 1$; $3 \%-p N 2 ; 3 \%-p N 3)$. Similar results were reported by Fan et al. (2015) and Hernandez-Aya et al. (2011) - they confirmed that the majority of their patients did not demonstrate lymph node involvement (57.5\% and 54\%). However, as opposed to our analysis, both research groups observed a greater percentage of $\mathrm{pN} 2$ and $\mathrm{pN} 3$ (pN2 - 9.5\%, pN3 - 8.3\%; pN2 - 8.7\%; pN3 - 6.1\%). Studies conducted by Dent et al. (2007) demonstrated distinctive results with the majority of TNBC patients presenting nodal metastases $[13,15,16]$.

In all examined triple-negative tumors histological grading was assessed and $6 \%$ of them were stated as G1, 51\% G2 and 43\% G3. Fan et al. (2015) obtained similar results, assessing 45.7\% of cancer in the TNBC group as G3. A much higher percentage of $\mathrm{G} 3$ patients with triple-negative tumors was reported by Nabi et al. (2016) and Rambau et al. (2014) (56\%; 85\%) [15, 17, 18].

Osteopontin is proved to be a specific phosphorylated glycoprotein playing a key role in many physiological processes such as osteoclastogenesis, angiogenesis and cell division [19]. In the past records higher expression of osteopontin was determined in cancer tissues, in comparison to healthy ones [4]. Recent studied confirmed that a higher level of osteopontin expression correlates with faster relapse and shorter OS [4].

The main aim of our study was to evaluate the correlation between expression of osteopontin and patient age, histological grading, tumor size and lymph node metastases. Our analysis revealed a statistically significant association between osteopontin expression and lymph node involvement - it could suggest that osteopontin may become a new marker of triple-negative breast cancer invasiveness. In our study an average level [++] of osteopontin expression was noted in $82 \%$ of patients with TNBC and lymph nodes metastases, whereas the same level of osteopontin expression was found only in $6 \%$ of patients without nodal involvement. However, it is worth pointing out that OPN was expressed in all TNBC cases and it was the level of expression that correlated with lymph node metastases, rather than expression itself. This indicates that OPN might be an unspecific marker. Moreover, our study lacks information about the clinical course of the patients whose tissue samples were included, preventing us from expanding our analysis to whether the in creased occurrence of lymph node metastases in fluences the clinical outcome. Allan et al. (2006) and Rudland et al. (2002) reported similar results, finding higher expression of osteopontin in tumors obtained from patients with nodal metastases, but it had no statistical significance ( $p=0.69$; $p=0.17)[20,21]$. Rudland et al. (2002) confirmed the association between osteopontin expression and level of histological grading (G1-G3). They assessed $30 \%$ of OPN-positive tumors as G3 in comparison to $17 \%$ of those that were without osteopontin expression. Likewise, their study demonstrated that an increased level of osteopontin is associated with decreased disease-free survival (DFS) and OS of the patients. Bramwell et al. (2014), Xu et al. (2015) and Thorat et al. (2013) studied the correlation between OPN and grading, tumor size and nodal involvement but they did not obtain any statistically significant results [20-24]. In their research Marcil et al. (2009) revealed OPN-positive tumors in $93 \%$ of patients with nodal metastases, whereas only $75 \%$ of patients without nodal involvement showed expression of osteopontin. Sun et al. (2012) and Hu et al. (2005) obtained similar results, stating that in patients with metastasis to lymph nodes OPN-positive tumors occur more frequently. There are conflicting reports regarding the association between osteopontin expression and grading. Marcil et al. (2009) and Rud et al. (2012) found a positive correlation between given factors, whereas Boldrini et al. (2005) and Donati et al. (2005) found this correlation negative [19, 25-29].

Weber et al. (2010) conducted a meta-analysis of 228 publications about osteopontin and its role as a marker for cancer aggressiveness and patient survival. After carrying out a comprehensive analysis they concluded that osteopontin is a valuable marker for patient survival concerning breast cancer, prostate cancer, head and neck cancers and liver cancer. Patients with OPN-positive tumors had lower overall and relapse-free survival. Weber et al. (2010) also confirmed the association between higher expression of osteopontin and lymph node metastases in eight cancers, including breast, lung, head and neck, gastric and esophageal cancer [30].

Various studies concentrate on mechanisms through which increased OPN expression promotes cancer progression, as described above. It appears that OPN plays important stimulating roles at every step of tumor aggressiveness: inducing cell proliferation [31], angiogenesis [32], mediating epithelia-mesenchymal transition [33] and, thus, development of distant metastases [34]. 
Studies concerning the structure of the OPN gene identified several enhancers enabling different transcriptional factors to influence the intensification of OPN gene transcription [35]. Among those is activator protein-1 (AP-1), a complex hetero- or homodimer protein of Jun and Fos oncogenic protein families [36]. Its function is currently being studied in various neoplasms, including triple-negative breast cancer, where it was shown to facilitate the progression of the tumor, for example by suppressing the expression of E-cadherin, decreasing cell-to-cell adhesion [37]. It would be worth considering the possibility of expression of OPN as a marker of AP-1 activation, which itself facilitates metastatic spread of the disease. Description of the Ras-activated enhancer in the promoter of the OPN gene [38] indicates that OPN expression might also be upregulated due to Ras oncogene activity, which is infrequent, but present in some cases of triple-negative breast cancer [39]. This suggests that increased expression of OPN observed in triple-negative breast cancer may result from enhanced transcription due to presence of oncogenic transcription factors. However, this matter requires detailed research.

Xu et al. (2016) conducted a study on mixed cell co-cultures of mammary fibroblasts with altered T-lymphoma invasion and metastasis-inducing protein 1 (Tiam1) expression and breast cancer cells. Decreased Tiam1 expression in fibroblasts resulted in increased secretion of osteopontin, leading to long-term increase of invasiveness in associated human breast cancer lines. The authors concluded that the Tiam1-OPN signaling pathway may regulate breast cancer invasiveness by causing epigenetic alterations of breast cancer stem cells and could be a potential therapeutic target [40].

Pio et al. (2017) studied ALDHhiCD44+CD24breast cancer cell migration in bone marrow-conditioned media in vitro. Their results showed that bone-derived OPN increased the migration and promoted maintenance of the stem-like behavior of breast cancer cells. They also demonstrated that the mechanism of this dependence is mediated by interactions between OPN and CD-44 and RGD-dependent integrins. In the studied cells, bone-derived OPN activated the downstream signaling pathway involving phosphorylation of WNK-1 and PRAS40 [41].

Osteopontin is not only correlated with invasiveness but also is suspected to be associated with the response to chemotherapy. OPN expression is always correlated with vasculogenic mimicry (VM) - a new model of neovascularization based on a microvascular channel made up of non-endothelial cells [42]. In the Gu et al. (2017) study, 80 out of 200 analyzed breast cancer sam- ples demonstrated positive expression of OPN. They proved that concurrence of OPN expression and VM might be used as a predictive factor for efficiency of neoadjuvant chemotherapy due to the significant correlation between its expression and pathological complete response [43]. The addition of one splice variant of OPN (exon-4) is suggested to be used in standard breast cancer immunohistochemistry owing to its potential in making decisions regarding the way of treatment. In the study conducted by Zduniak et al. (2016) osteopontin exon 4 was associated with a favorable response to tamoxifen and a poor response to CMF chemotherapy (cyclophosphamide, methotrexate, fluorouracil) [44]. What is more, high expression of OPN mRNA is correlated with reduced DFS and OS [45].

In conclusion, our study confirmed that invasive ductal carcinoma comprises the most numerous groups among all histological types of breast cancer. Furthermore, the analysis conducted on patients with triple-negative breast cancer confirmed the association between nodal metastases (pNO-pN3) and tumor size (pT1-pT4) and highlighted the statistically significant correlation between osteopontin expression and lymph node involvement, which may suggest osteopontin's important role in the invasiveness of triple-negative breast cancer.

\section{Conflict of interest}

The authors declare no conflict of interest.

\section{References}

1. Senger DR, Wirth DF, Hynes RO. Transformed mammalian cells secrete specific proteins and phosphoproteins. Cell 1979; 16: 885-93.

2. Standal T, Borset M, Sundan A. Role of osteopontin in adhesion, migration, cell survival and bone remodeling. Exp Oncol 2004; 26: 179-84.

3. Mituś JW, Sas-Korczyńska B, Ryś J. Metaplastic breast cancer with rapidly progressive recurrence in a young woman: case report and review of the literature. Arch Med Sci 2016; 12: 1384-8.

4. Mrochem J, Bartnik W. Osteopontyna - nowy marker w chorobach nowotworowych. Wsp Onkol 2008; 12: 349-53.

5. Badve S, Dabbas DJ, Schnitt Baehner FL, et al. Basal-like and triple negative breast cancers: a critical review with an emphasis on the implications for pathologists and oncologists. Mod Pathol 2011; 24: 157-67.

6. Engebraaten O, Vollan HK, Børresen-Dale AL. Triple-negative breast cancer and the need for new therapeutic targets. Am J Pathol 2013; 183: 1064-74.

7. Nowacka-Zawisza M, Krajewska WM. Potrójnie negatywny rak piersi: molekularna charakterystyka i potencjalne strategie terapeutyczne. Postepy Hig Med Dosw 2013; 67: 1090-7.

8. Lehmann BD, Pietenpol JA, Tan AR. Triple-negative breast cancer: molecular subtypes and new targets for therapy. Asco Educational Book 2015; 31-39. 
9. Kołacińska A, Chałubińska J, Błasińska-Morawiec M, et al. Pathological complete response in younger and older breast cancer patients. Arch Med Sci 2012; 8: 310-5.

10. Cao MD, Lamichhane S, Lundgren S, et al. Metabolic characterization of triple negative breast cancer. BMC Cancer 2014; 14: 941.

11. Wong-Brown MW, Meldrum CJ, Carpenter JE, et al. Prevalence of BRCA1 and BRCA2 germline mutations in patients with triple-negative breast cancer. Breast Cancer Res Treat 2015; 150: 71-80.

12. Bhoo-Pathy N, Verkooijen HM, Wong FY, et al. Prognostic role of adjuvant radiotherapy in triple-negative breast cancer: a historical cohort study. Int J Cancer 2015; 137: 2504-12.

13. Dent R, Trudeau M, Pritchard KI, et al. Triple-negative breast cancer: clinical features and patterns of recurrence. Clin Cancer Res 2007; 13: 4429-34.

14. Badowska-Kozakiewicz A, Budzik MP, Liszcz A, et al. Clinicopathological factors associated with novel prognostic markers for patients with triple negative breast cancer. Arch Med Sci 2018; 14: 1439-49.

15. Fan Y, Ding X, Xu B, et al. Prognostic significance of single progesterone receptor positivity. Medicine 2015; 94: 1-7.

16. Hernandez-Aya LF, Chavez-MacGregor M, Lei X, et al. Nodal status and clinical outcomes in a large cohort of patients with triple-negative breast cancer. J Clin Oncol 2011; 29: 2628-34.

17. Nabi MG, Ahangar A, Wahid MA, Kuchay S. Clinicopathological comparison of triple negative breast cancers with non-triple negative breast cancers in a hospital in North India. Niger J Clin Pract 2015; 18: 382-6.

18. Rambau P, Masalu N, Jackson K, Chalya P, Serra P, Bravaccini S. Triple negative breast cancer in a poor resource setting in North-Western Tanzania: a preliminary study of 52 patients. BMC Research Notes 2014; 399: 2-6.

19. Macrì1 A, Versaci A, Lupo G, et al. Role of osteopontin in breast cancer patients. Tumori 2009; 95: 48-52.

20. Allan AL, George R, Vantyghem SA, et al. Role of the integrin-binding protein osteopontin in lymphatic metastasis of breast cancer. Am J Pathol 2006; 169: 233-46.

21. Rudland PS, Platt-Higgins A, El-Tanani M, et al. Prognostic significance of the metastasis-associated protein osteopontin in human breast cancer. Cancer Res 2002; 62: 3417-27.

22. Bramwell V, Tuck AB, Chapman JA, et al. Assessment of osteopontin in early breast cancer: correlative study in a randomised clinical trial. Breast Cancer Res 2014; 16: 1-10.

23. Xu YY, Zhang Y, Lu WF, Mi YJ, Chen YQ. Prognostic value of osteopontin expression in breast cancer: a meta-analysis. Mol Clin Oncol 2015; 3: 357-62.

24. Thorat D, Sahu A, Behera R, et al. Association of osteopontin and cyclooxygenase-2 expression with breast cancer subtypes and their use as potential biomarkers. Oncol Lett 2013; 6: 1559-64.

25. Sun Y, Li D, Lv XH, et al. Roles of osteopontin and matrix metalloproteinase-7 in occurrence, progression, and prognosis of nonsmall cell lung cancer. J Res Med Sci 2015; 20: 1138-46.

26. Hu Z, Lin D, Yuan J, et al. Overexpression of osteopontin is associated with more aggressive phenotypes in human non-small cell lung cancer. Clin Cancer Res 2005; 11: 4646-52.

27. Boldrini L, Donati V, Dell'Omodarme M, et al. Prognostic significance of osteopontin expression in early-stage non-small-cell lung cancer. Br J Cancer 2005; 93: 453-7.

28. Donati V, Boldrini L, Dell'Omodarme M, et al. Osteopontin expression and prognostic significance in non-small cell lung cancer. Clin Cancer Res 2005; 11: 6459-65.
29. Rud AK, Lund-Iversen M, Berge $G$, et al. Expression of S100A4, ephrin-A1 and osteopontin in non-small cell lung cancer. BMC Cancer 2012; 13: 540.

30. Weber GF, Lett GS, Haubein NC. Osteopontin is a marker for cancer aggressiveness and patient survival. Br J Cancer 2010; 103: 861-9.

31. Angelucci A, Festuccia C, Gravina GL, et al. Osteopontin enhances the cell proliferation induced by the epidermal growth factor in human prostate cancer cells. Prostate 2004; 59: 157-66.

32. Wang Y, Yan W, Lu X, et al. Overexpression of osteopontin induces angiogenesis of endothelial progenitor cells via the av $33 / \mathrm{PI} 3 \mathrm{~K} / \mathrm{AKT} / \mathrm{eNOS} / \mathrm{NO}$ signaling pathway in glioma cells. Eur J Cell Biol 2011; 90: 642-8.

33. Kothari AN, Arffa ML, Chang V, et al. Osteopontin a master regulator of epithelial-mesenchymal transition. J Clin Med 2016; 5: 23.

34. Jia R, Liang $Y$, Chen R, et al. Osteopontin facilitates tumor metastasis by regulating epithelial-mesenchymal plasticity. Cell Death Dis 2016; 7: 2564.

35. Hijiya N, Setoguchi M, Matsuura K, et al. Cloning and characterization of the human osteopontin gene and its promoter. Biochemical J 1994; 303: 255-62.

36. Rodrigues LR, Teixeira JA, Schmitt FL, Paulsson M, Lindmark-Mänsson $\mathrm{H}$. The role of osteopontin in tumor progression and metastasis in breast cancer. Cancer Epidemiol Biomarkers Prev 2007; 16: 1087-97.

37. Zhao C, Qiao Y, Jonsson P, et al. Genome-wide profiling of AP-1-regulated transcription provides insights into the invasiveness of triple-negative breast cancer. Cancer Res 2014; 74: 3983-94.

38. Guo X, Zhang YP, Mitchell DA, Denhardt DT, Chambers AF. Identification of a ras-activated enhancer in the mouse osteopontin promoter and its interaction with a putative ETS-related transcription factor whose activity correlates with the metastatic potential of the cell. Mol Cell Biol 1995; 15: 476-87.

39. Giltnane J, Balko J. Rationale for targeting the Ras/MAPK pathway in triple-negative breast cancer. Discovery Med 2014; 17: 275-83.

40. Xu K, Tian X, Oh SY et al. The fibroblast Tiam1-osteopontin pathway modulates breast cancer invasion and metastasis. BCR 2016; 18: 1-14.

41. Pio GM, Xia Y, Piaseczny MM, Chu JE, Allan AL. Soluble bone-derived osteopontin promotes migration and stemlike behavior of breast cancer cells. PLoS One 2017; 12.

42. Kadkol SS, Lin AY, Barak V, et al. Osteopontin expression and serum levels in metastatic uveal melanoma: a pilot study. Invest Ophthalmol Vis Sci 2006; 47: 802-6.

43. Gu M, Zheng X. Osteopontin and vasculogenic mimicry formation are associated with response to neoadjuvant chemotherapy in advanced breast cancer. Onco Targets Ther 2017; 10: 4121-7.

44. Zduniak K, Agrawal A, Agrawal S, et al. Osteopontin splice variants are differential predictors of breast cancer treatment responses. BMC Cancer 2016; 16: 441.

45. Psyrri A, Kalogeras K, Wirtz RM, et al. Association of osteopontin with specific prognostic factors and survival in adjuvant breast cancer trials of the Hellenic Cooperative Oncology Group. J Transl Med 2017; 15: 30. 